\title{
AUTOLOG - SOLUÇÃO EM AUTOMAÇÃO LOGÍSTICA*
}

Fabrício Tibúrcio Sllva Araújo

\section{Resumo}

O AutoLog é uma solução em tecnologia de automação e informação para controle absoluto do carregamento e descarregamento de caminhões em um grande cliente no ramo de fertilizantes. Seu objetivo é garantir uma operação autônoma que otimize os lucros e reduza os custos em logística. Este trabalho visa demonstrar o problema que originou a solução, a metodologia utilizada no seu desenvolvimento e o seu objetivo final.

Palavras-chave: Logística; Caminhões; Automação; Informação.

\section{Abstract}

\section{AUTOLOG - SOLUTION IN LOGISTICS AUTOMATION}

AutoLog is a solution in automation and information technology that allows absolute control in truck loading and unloading in a big customer of fertilizer market. Autolog's target is to ensure an autonomous operation which optimizes profit and reduce cost in logistics. This paper will demonstrate the problem which originated the solution, its methodology used in development and its final purpose.

Keywords: Logistics; Trucks; Automation; Information.

1 Engenheiro de Controle e Automação, Lynx Otimização de Processos, Belo Horizonte, Minas Gerais - Brasil. 


\section{INTRODUÇÃO}

O Autolog - Automação Logística, surgiu da necessidade de se gerenciar todo o fluxo de carregamento e descarregamento de caminhões de uma grande empresa no mercado de fertilizantes nacional garantindo assertividade, organização e redução de custos na operação.

Uma série de problemas no processo logístico predecessor as Autolog fomentaram esta demanda. Abaixo é possível ver um esquemático que exibe algumas das áreas da unidade e os seus respectivos pontos de possíveis melhorias implantadas pela solução:

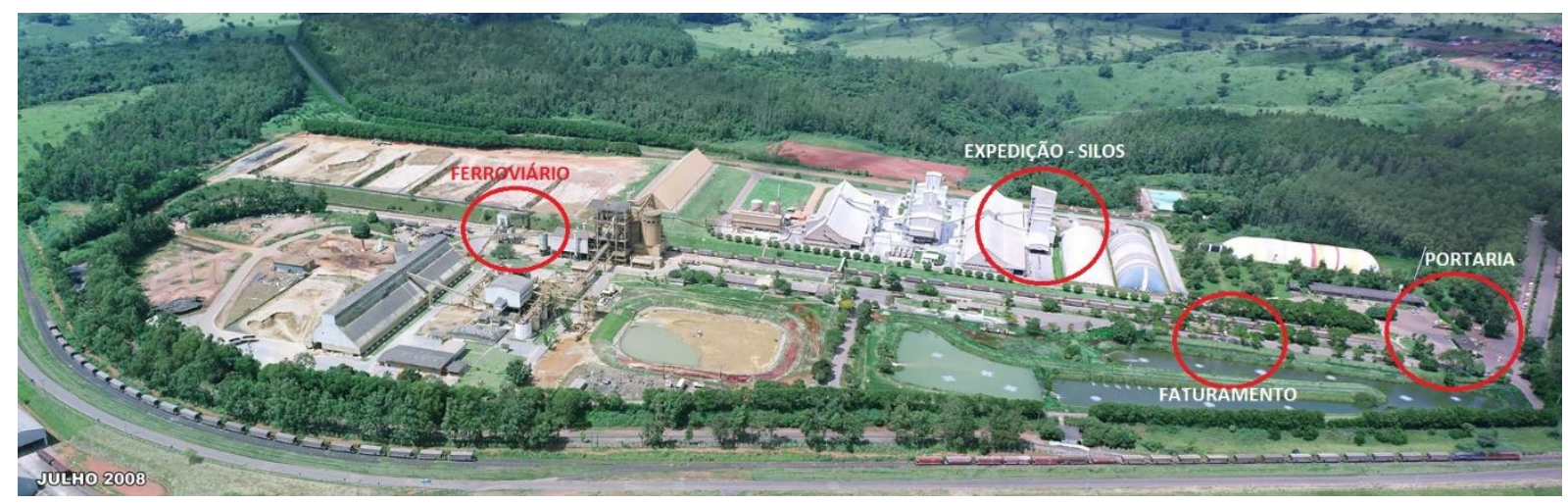

\subsection{Portaria / Pátio de Espera}

- Filas grandes de caminhões aguardando entrada sem informações atualizadas e de fácil acesso de seus agendamentos. As informações são passadas por operador da triagem que não conhece todas as variáveis do processo para controlar entradas / saídas;

- Caminhoneiros chegam fora do horário agendado e causam desgaste do operador da triagem para informá-los da impossibilidade do acesso;

- Todo o controle de entrada e saída é feito pela triagem gerando uma grande centralização do processo;

- Sistema de agendamento de caminhões não leva em conta as variáveis de carregamento / descarregamento como o tempo de cada etapa do processo. Isso leva a atrasos no atendimento e certas até a impasses devido a indisponibilidade de atender aos caminhões já presentes na unidade;

- Acesso interno manualmente autorizado por pessoal de segurança que é responsável por abrir e fechar cancelas confiando no serviço da triagem previamente realizado. Tal pessoal deveria estar focado somente na garantia da segurança do local e não com as peculiaridades do processo logístico;

- Toda a comunicação da triagem com as áreas da unidade é feita via rádio ou telefone levando a possíveis falhas de entendimento e falhas no processo de carregamento / descarregamento;

- Definição de quais documentos devem ser entregues ao caminhoneiro é responsabilidade do operador da triagem; 


\subsection{Faturamento}

- Reporte de extravios de materiais com formalização incorreta de pesos nos documentos de saída dos caminhões;

- Pesagens inconsistentes devido a posicionamento incorreto do caminhão sobre a balança de entrada / saída (na lateral, frente, trás);

- Falta de respeito / atenção dos caminhoneiros às filas de caminhões para a pesagem causando impasses no processo;

- Necessidade de trabalhos repetitivos dos operadores que poderiam estar focados na qualidade do processo;

- Falta de comunicação formal com o motorista sobre como proceder no processo;

- Validação de inconsistências de pesagem é feita e informada pelos operadores sendo um ponto de avaliação pessoal;

- Entrada simultânea de caminhões sobre a balança causando impasses no processo;

\subsection{Expedição - Silos}

- Reporte de extravios de materiais com formalização incorreta de pesos nos documentos de saída dos caminhões;

- Pesagens inconsistentes devido a posicionamento incorreto do caminhão sobre a balança de entrada / saída (frente, trás);

- Todo o processo de comunicação com o motorista é pessoal;

- Registro de pesagem é feito manualmente;

\subsection{Ferroviário}

- Registro de pesagem dos vagões é feito manualmente ocasionando erros;

\subsection{Geral}

- Acessos incorretos de caminhões a locais não permitidos de acordo com a sua operação;

- Locais onde não se possuem automação de balança não registram a fiscalização e pesagem dos caminhões;

- Descentralização de sistemas de agendamento, processo e automação; 


\section{MATERIAIS E MÉTODOS}

A solução Autolog permite que o fluxo de carregamento e descarregamento de caminhões e circulação interna aconteça de forma praticamente autônoma com mínima interferência humana.

Foi feito um grande estudo em conjunto com o cliente afim de automatizar e otimizar o processo logístico que possui características cíclicas e assim poderia de forma ágil atingir estes objetivos.

Para tal objetivo, o AutoLog foi elaborado como uma solução convergente entre Tecnologia de Informação (TI) e Tecnologia de Automação (TA) que reúne as técnicas e tecnologias mais utilizadas nessas duas disciplinas.

Em TI, pode-se citar tecnologias como C\# .NET, SQL Server, MVC e OPC. Em TA utiliza-se PLCs Siemens para controle de posicionamento e liberação de balanças, IHMs Dakol, cancelas que suportam alta frequência de uso, leitores RFID Accura para reconhecimento de smartcards dos motoristas, painéis de LED informativos, antenas wi-fi Ubiquiti para comunicação com tablets, etc.

\subsection{Programação da Solução}

A solução foi desenvolvida em fases para garantir que as mudanças de conceito sejam assimiladas com poucos efeitos colaterais.

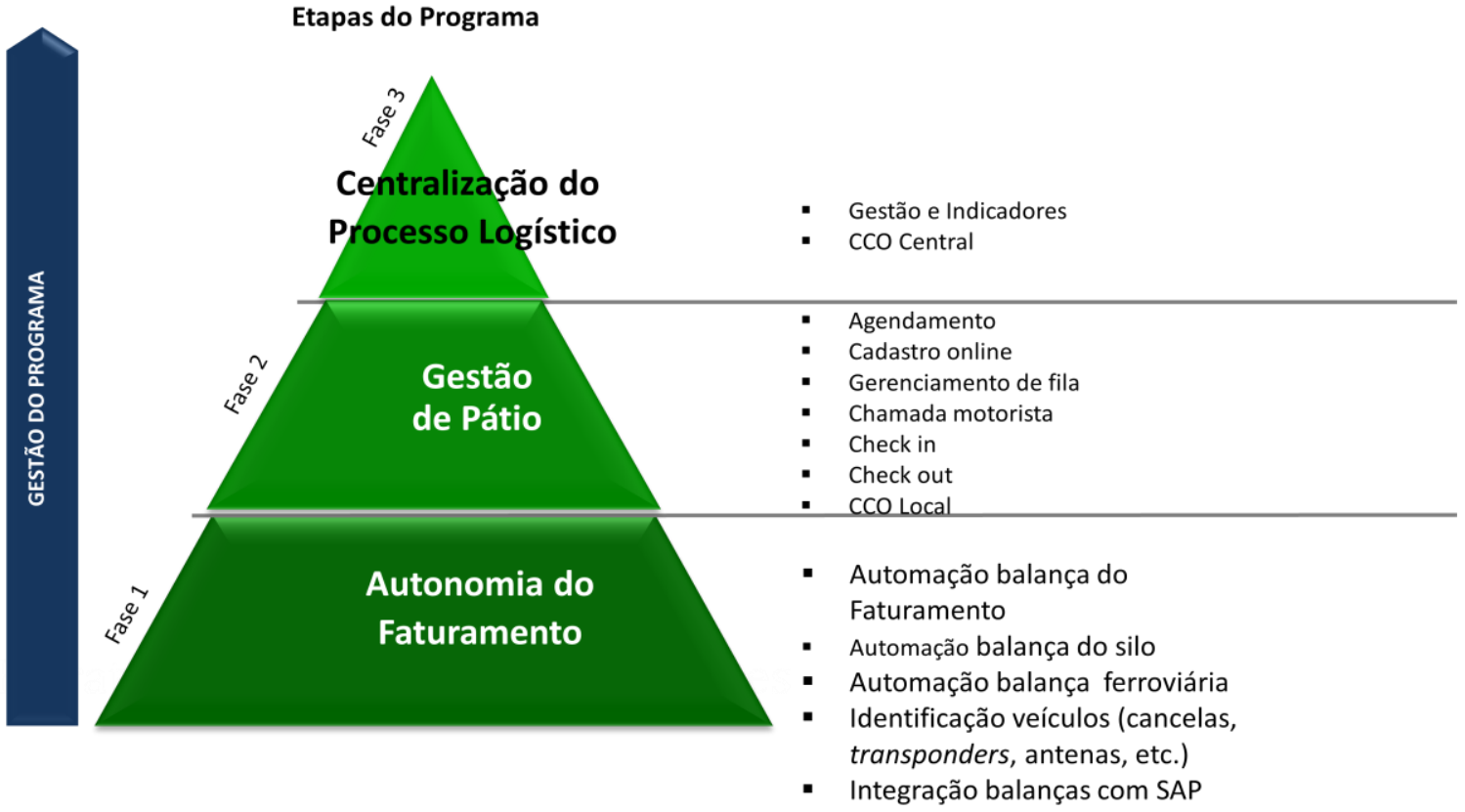

Figura 1. Arquitetura da Solução 


\subsection{Etapas do Processo}

O fluxo proposto pela solução se inicia pela criação de uma demanda pelo cliente final no sistema gerando um agendamento. Esse agendamento, inicia uma solicitação de entrada do caminhão nas estações para carregamento ou descarregamento. Todas as operações feitas pelos motoristas desde sua chegada à estação são monitoradas e autorizadas pela solução via sistema web e controle de periféricos como painéis, sensores, totens RFID e cancelas de acesso.

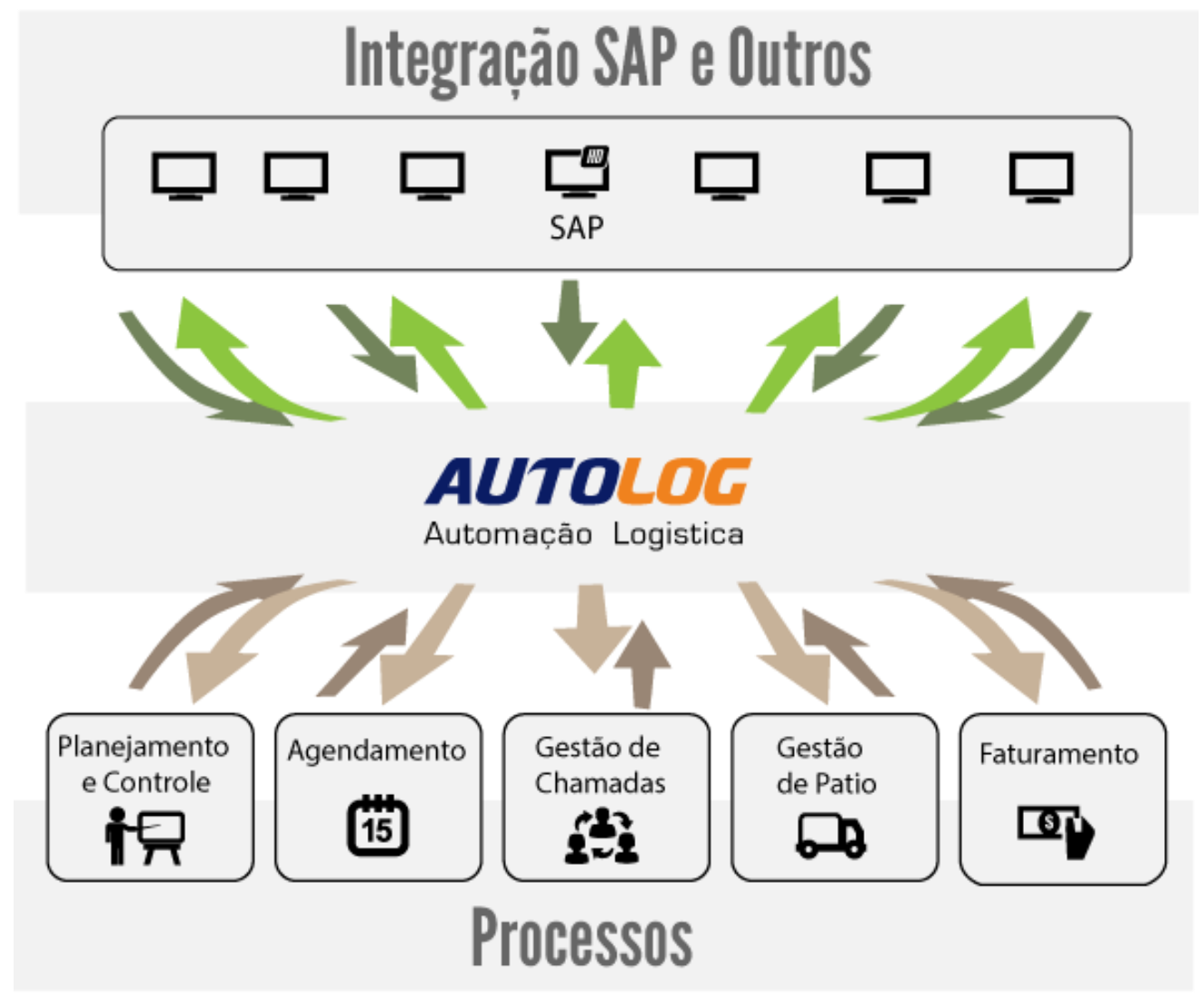

Figura 2. Autolog - Gestão Completa em Logística

\section{- Agendamento}

O Agendamento é feito em um sistema que é parte da solução Autolog, chamado de Autolog - Agendamento. Seu objetivo é disponibilizar aos clientes finais e transportadoras a possibilidade de agendar operações de caminhões nas unidades desse grande fornecedor de fertilizantes do Brasil. Através do Autolog Agendamento é possível também acompanhar todo o fluxo do caminhão desde a sua chegada à unidade até a sua liberação. 


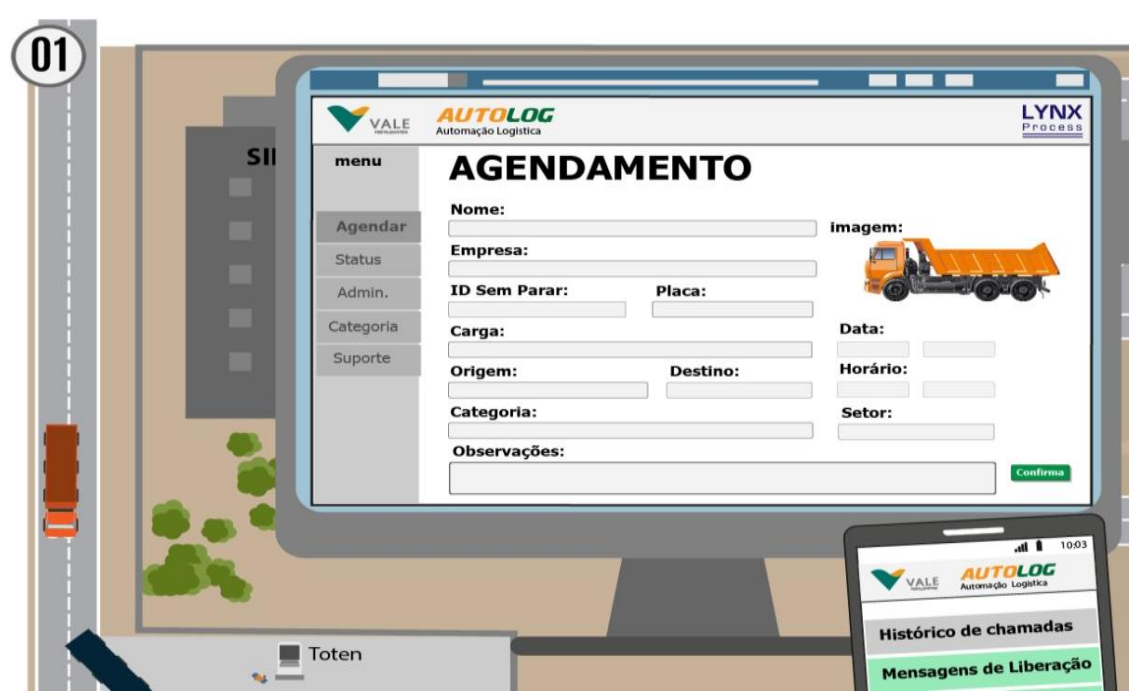

Figura 3. Sistema Autolog - Agendamento - Controle de Transportadores e Clientes

\section{- Chamada de Caminhões}

Ao receber um agendamento, o Autolog gerencia a chamada de caminhões estacionados no pátio da unidade de acordo com uma série de critérios que garantam o controle, a segurança e a eficiência do processo de carregamento e descarregamento.

A chamada é feita através de voz sintetizada em cornetas localizadas no pátio de caminhões da unidade.

\section{- Check-In}

Ao ser chamado o motorista se apresenta no totem multimídia de Check-In que registra sua entrada e o fornece um smartcard para acesso aos pontos de controle. O motorista só tem acesso aos pontos que foram previamente cadastrados no sistema para a sua operação específica. 

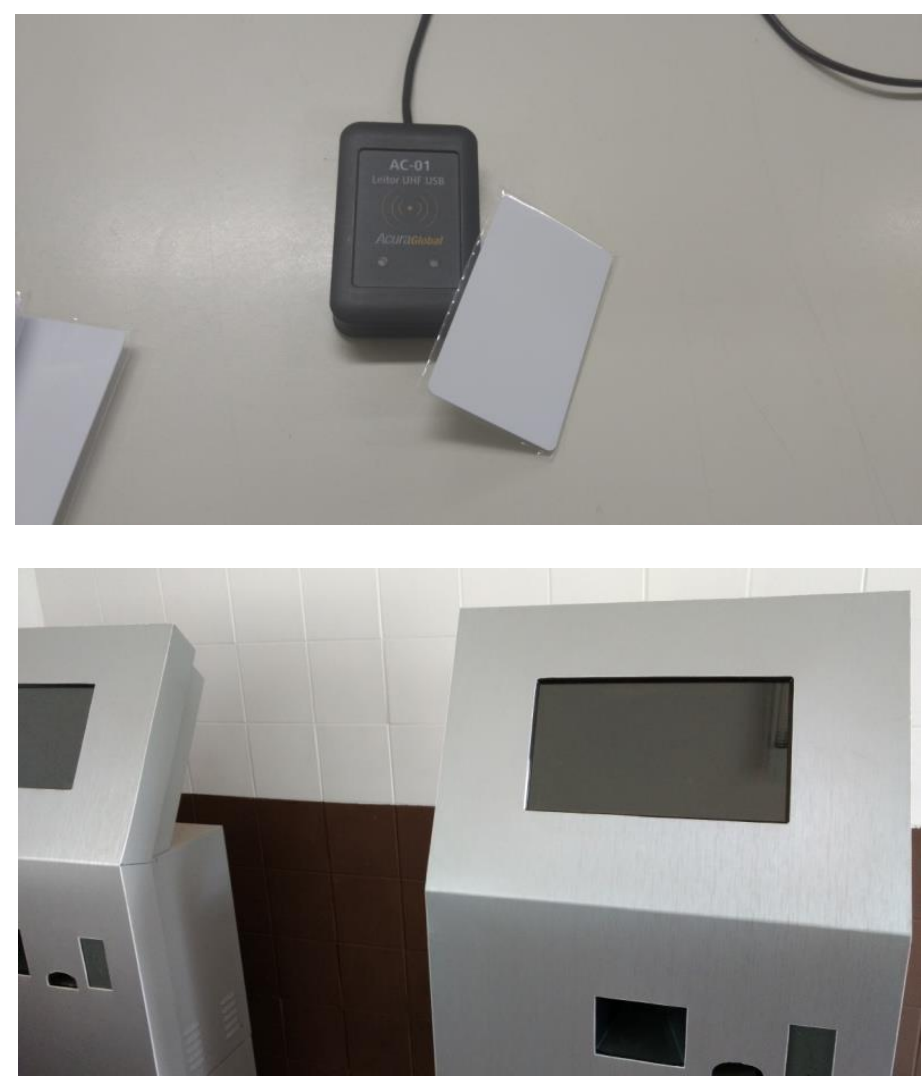

Figura 4. Smartcards de acesso à unidade

\section{- Acessos}

O motorista é orientado no procedimento a seguir e para liberar entrada em qualquer ponto da unidade precisa posicionar seu cartão em leitoras RFID que se comunicam com o Autolog e validam se o motorista tem permissão de acesso.

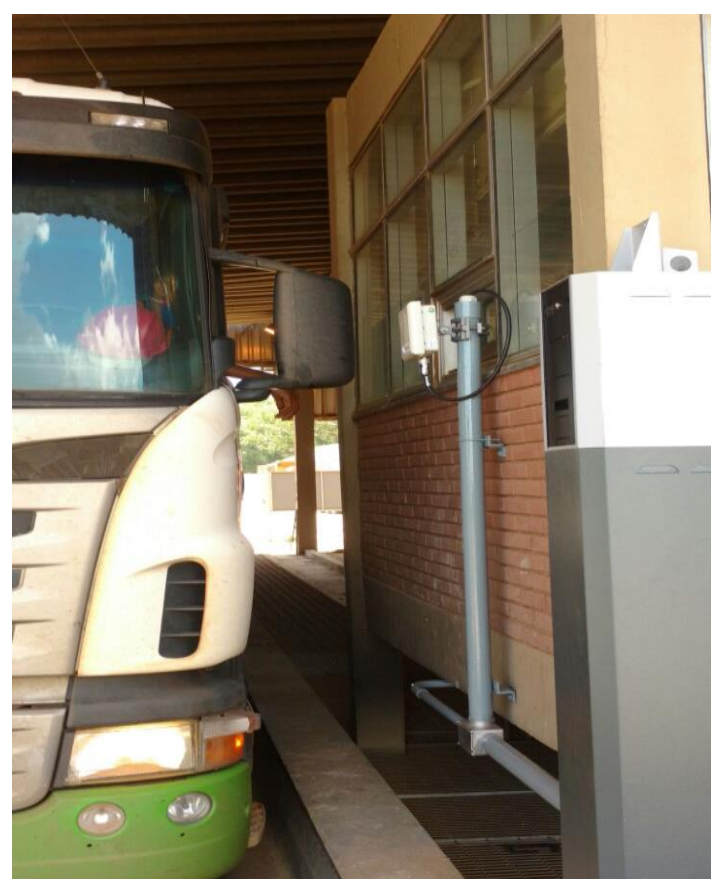

Figura 5. Validação de acesso via leitora de smartcards 


\section{- Pesagens}

O processo de pesagem de tara e bruto são realizadas de forma autônoma após a validação do smartcard do motorista e da sua posição correta sobre as balanças rodoviárias. Todo o processo é instruído através de painéis de LED que informam o procedimento de pesagem ao operador bem como seu peso e liberação.

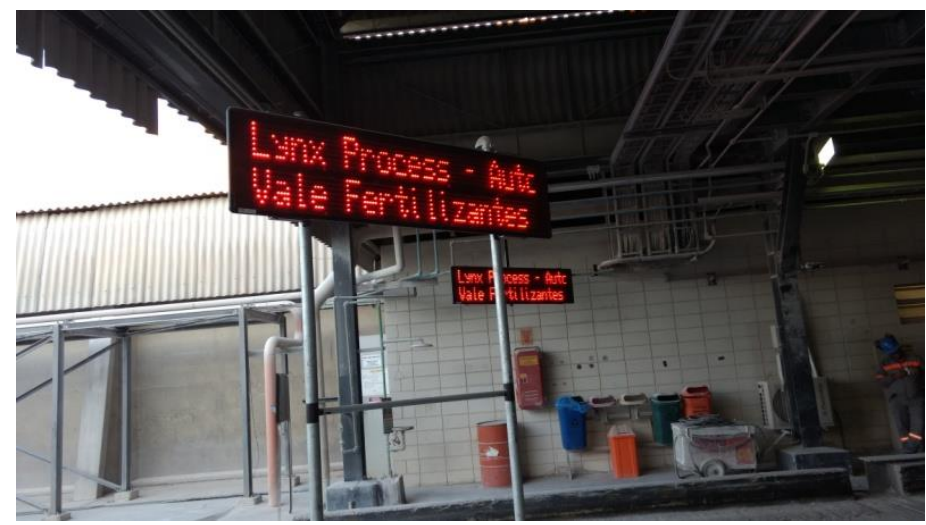

Figura 6. Processo de pesagem em balanças

Assim que o caminhão se posiciona corretamente na balança, o peso é lido e registrado no AutoLog. Se o caminhão estiver dentro dos parâmetros préestabelecidos, ele é liberado com a abertura das cancelas. Em caso contrário, o mesmo é direcionado para um fluxo alternativo para regularizar sua situação.

\section{- Faturamento}

Após finalizada a operação, o caminhão precisa ter sua documentação confeccionada para viagem. Todo esse processo é realizado baseando-se no fluxo realizado pelo caminhão na estação o que evita falhas humanas.

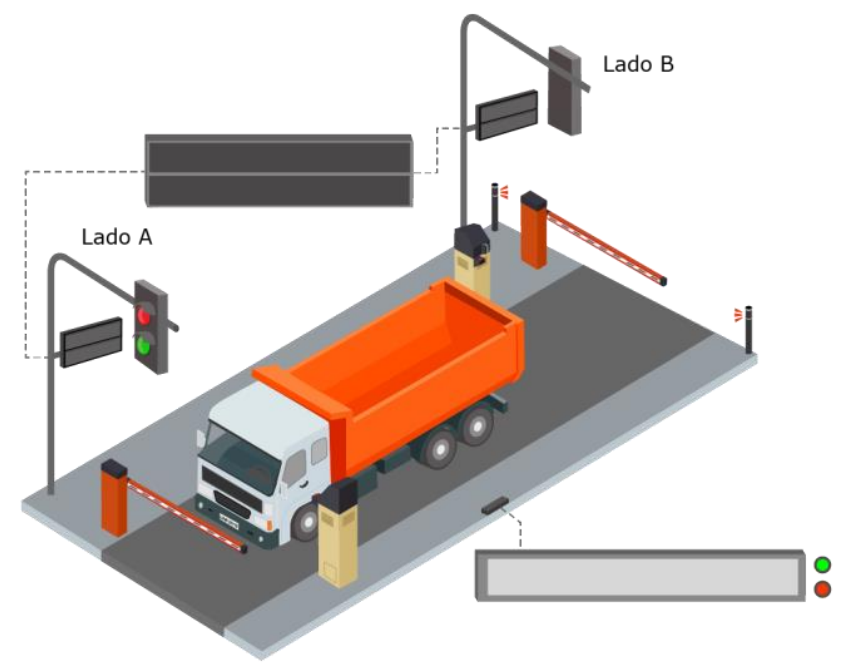

Figura 7. Faturamento do caminhão 


\section{- $\quad$ Check-Out}

Para sair da estação o motorista deve utilizar seu smartcard na cancela de saída e então devolvê-lo no totem de saída. O smartcard é então finalizado evitando novas operações com o mesmo.

\section{RESULTADOS E DISCUSSÃO}

O Autolog permite o aumento da lucratividade da empresa e redução de custos nos seguintes aspectos:

- Eliminação de extravios devido a ações de má-fé;

- Garantia no registro de dados de pesagem eliminando falhas humanas tanto dos motoristas quanto do pessoal de operação;

- Redução de pessoal de segurança, operação e controladoria do processo;

- Centralização de informações para todos os envolvidos no processo de acordo com cada permissão de acesso;

- Gerenciamento efetivo de atendimento de clientes finais;

- Controle absoluto de cada etapa do processo e no seu impacto nos agendamentos e chamadas de caminhões garantindo organização no fornecimento / recebimento;

- Padronização nos atendimentos a caminhoneiros;

- Histórico de todas as operações realizadas na unidade.

Como se pode observar o Autolog é uma ferramenta extremamente poderosa para qualquer processo logístico ao automatizar toda a cadeia e centralizar todas as informações que são importantes para garantir a robustez desse processo.

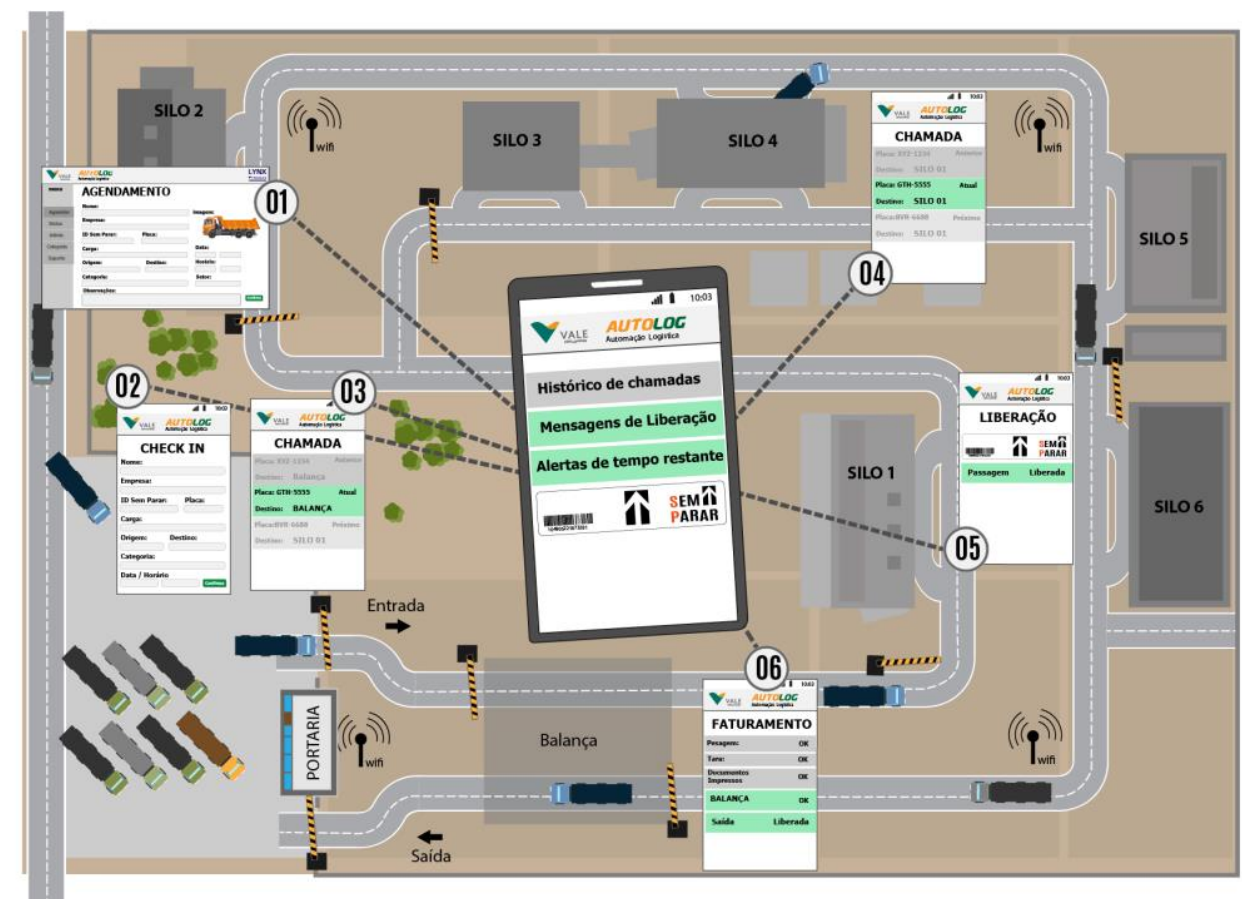

Figura 8. Visão geral do processo 


\section{CONCLUSÃO}

O Autolog é uma solução inovadora que resulta em um maior controle da unidade além de reduzir custos e aumentar a lucratividade do cliente final.

As necessidades de uma melhor gestão do processo ao evitar desvios operacionais e a falta de informações centralizadas são atendidas de forma concreta podendo-se obter resultados em curto prazo após a implantação da solução. 


\section{Agradecimentos}

Agradeço à equipe Lynx pelo empenho no desenvolvimento da solução e às unidades envolvidas no projeto pelo fornecimento de informações e engajamento na implantação da solução.

\section{REFERÊNCIAS}

1 Lynx Otimização de Processo. [acesso em 02 jun. 2017];11:74-92. Disponível em: http://www.tsaengenharia.com.br/site/?p=1590. 